dismantled. Some scientists believe that it will be possible to stuff the genie of regulation of recombinant DNA research back into the bottle. If so, what kind of a legacy will the recombinant DNA debate leave? Perhaps it is too early to clearly assess this question, but the following thoughts come to mind. The development and evolution of guidelines for recombinant DNA research provides a case-study in innovative formation of a policy to cope with uncertainties generated by a major expansion in human knowledge and power. Early discussion of the possibilities in public, a continuation of cautious research coupled with risk-assessment studies, and built-in mechanisms for modifying regulations in the light of new knowledge may prove to be useful principles in analogous future situations. In addition, the recombinant DNA debate has conveyed to a wide audience the vast potential of the 'synthetic biology' opened up by recombinant DNA techniques. Thoughtful consideration of the ends to which this potential is being and could be applied should commence, as concern over potential biohazards diminishes.

Richard Roblin was a member of the National Academy of Sciences Committee on Recombinant DNA Molecules and the organising committee for the 1975 Asilomar Conference on Recombinant DNA Molecules. He is now Head of the Molecular Biology of Tumor Cells Group, Cancer Biology Program, Frederick Cancer Research Center, Frederick, Maryland.

\section{Drives and action patterns}

\section{John R. Krebs}

The Origins and Rise of Ethology: The Science of the Natural Behaviour of Animals. By W. H. Thorpe. Pp. 174. (Heinemann Educational: London, UK; Praeger/Holt, Rhinehart and Winston/CBS: New York, 1979.) $£ 5.90$.

THIs book is an extended version of the first Niko Tinbergen lecture, given by Professor Thorpe to the Association for the Study of Animal Behaviour in 1974. He describes how ethology started, what it was like in the middle of the twentieth century and what it is about today. The middle section of the book, which is full of anecdotes and personal recollections of Professor Thorpe, is to my mind the best.

The early history of ethology is traced by Thorpe to John Ray, the seventeenth century British naturalist who, among many other things, did experiments on clutch size in birds. The subject in its present day sense (the naturalistic study of animal behaviour; not the "science of character-formation" as in the term used by J.S. Mill) emerged in France in the eighteenth and early nineteenth centuries through the writings of C.G. Leroy, J.B. Lamarck and E. Geoffroy-Saint-Hilaire. (Some readers may be amused to know that Leroy was gamekeeper of the area in France called Marly - virtually the same name as that given to the wood near Oxford in which R.A. Hinde carried out his thesis research nearly 200 years later.) Although Britain had a strong traditon of country naturalists in the eighteenth and nineteenth centuries, Thorpe rightly emphasises $D$. Spalding as the key British figure in the early development of ethology. Spalding pioneered experimental studies of behaviour development and had a great impact on Lloyd Morgan, who was influential in espousing a scientific, reductionist approach to the study of animal behaviour. Among early American students of behaviour, Thorpe mentions particularly the contributions of Whitman, Craig, Lashley and Wheeler; perhaps he should also have included W.C. Allee whose book The Social Life of Animals foreshadowed much that is current in ethological thinking. account, Thorpe moves to the period with which he is familiar from personal experience. In the 1930s and 1940s ethology became firmly established as a discipline distinct from other approaches to the study of behaviour, mainly through the work of Lorenz and Tinbergen. The account of this period is very revealing to those who have seen only only the later years of the era of these great men. Today, Lorenz's theories are viewed as somewhat old-fashioned and naive, but as Thorpe stresses "The very fact that Lorenz's early papers now appear so outdated is a tribute to their effectiveness.... It is the impetus which they gave to experimental work which has,

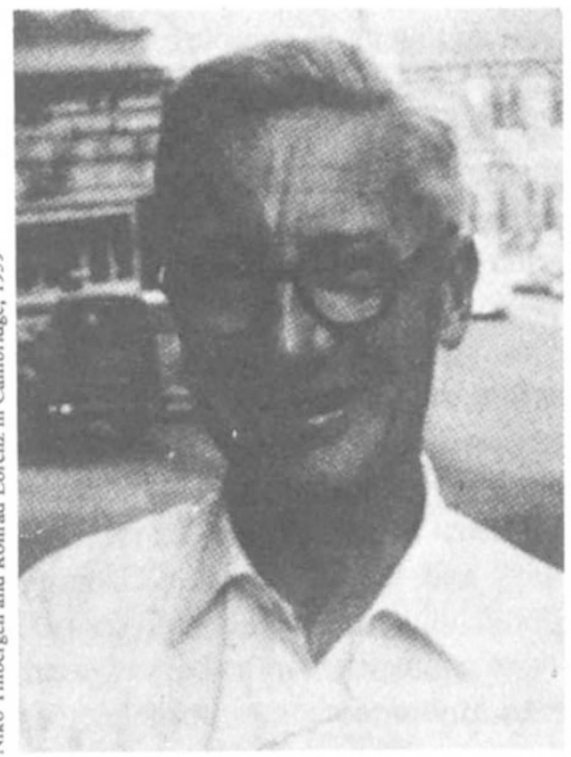

From this straightforward historical in a sense, rendered them so quickly out of date, although they are still of course extremely well worth reading".

According to Thorpe, the central problem facing ethologists in the 1930s was to elucidate the nature of instinctive behaviour. Although it was widely recognised that animals perform complicated "goal oriented" sequences of behaviour, such as nest-building and courting, without any particular training, there was no conceptual framework within which to analyse and dissect these instinctive behaviours. Lorenz provided the framework in a series of papers published in the decade 1931-41. Instincts were viewed as being made up of simple stereotyped, inborn movements (fixed action patterns) linked together by more flexible and modifiable goal oriented behaviour (appetitive behaviour). Both of these were thought to be driven by "specific drives", (physiological mechanisms). Usually the fixed action patterns were released by a specific stimulus (releaser) and they were consummatory in the sense of dissipating the specific drive for that appetitive behaviour and fixed action pattern sequence. Internal drive was considered to then gradually build up until a fixed action pattern could discharge it again. If no suitable stimulus appeared, the action might go off "in a vacuum". Professor Thorpe stresses that this theoretical framework was valuable bacause it immediately led people to investigate in detail the nature of instinctive behaviour. For example, physiological and endocrinological studies of drives, perceptual studies of releasers, and genetic studies of fixed action patterns were set up to test Lorenz's ideas.

While providing a lucid account of Lorenzian theory, Professor Thorpe also tells us many anecdotes from the immediate post-War years. Stories are told of how Lorenz nearly went to Cambridge

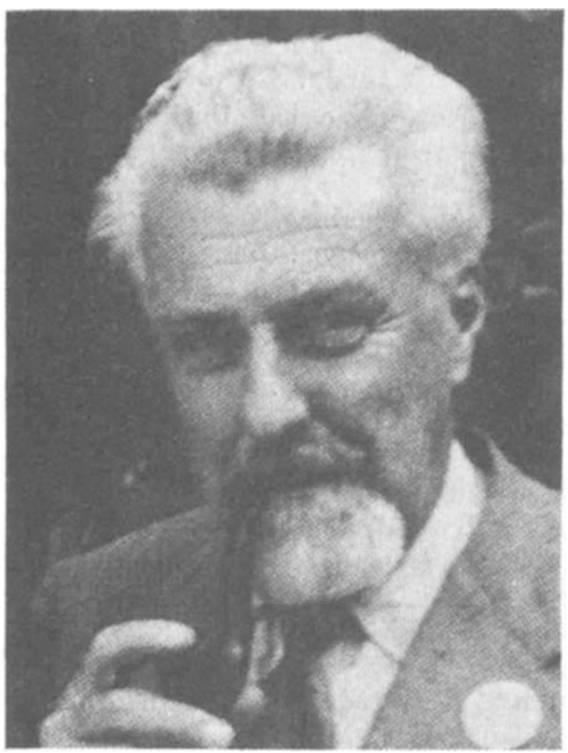


instead of to the Max Planck Institute; how Lorenz and Tinbergen quacked like ducks to put off two predatory women; and how Thorpe himself was asked to present a paper of "about two hours" when he turned up at the First International Ethological Conference! It would be nice if this part of the book were expanded into a full volume at a later date.

The last chapter, on the present position of ethological concepts and research, is also fascinating from an historical viewpoint. It illustrates how the same events can be seen in a totally different light by observers from two different generations. In Thorpe's view, ethology today still works within the Lorenzian framework, and the questions asked still deal with fixed action patterns, drive, displacement activities, releasers, and so on. The details have changed very much, but the conceptual armoury is still the same. To an ethologist trained a generation later, the view is that ethology (in particular British and American ethology) underwent a purge in the 1950 s and early 1960 s, mainly due to the masterly critiques of R.A. Hinde; in this much of the earlier Lorenzian theorising was rejected and replaced with a hard-headed, reductionist approach. This created a spartan atmosphere in which theorising was definitely out, and hard data in. Then the early 1970s saw a flowering of new theoretical ideas and new questions about behaviour, this time linking ethology with population genetics and evolution. Perhaps there will be a new purge in the 1980s.

Neither of these contrasting views about present-day ethology can be said to be right or wrong: they emphasise that in spite of our attempts to be objective about the behaviour of animals, the interpretation of our own history is very much subjective. $\square$

John R. Krebs is Lecturer in Zoology at the Edward Grey Institute of Field Ornithology, University of Oxford, UK.

\section{Selected genetics}

\section{J. Lawrence}

Understanding Genetics. By E.B. Ford. Pp. 201. (Faber and Faber: London, 1979.) $£ 7.25$.

PROFESSOR FORD tells us in the preface that this book is an attempt to meet the needs of those who, whether they be men of general education or scholars in other fields of learning, wish to know something of the theoretical aspects of genetics. This is a laudable, though ambitious, objective, for if such an attempt is to succeed, the author will have to possess an unusually wide and deep knowledge of the subject, so as to be able to give both an adequate coverage of it and to deal with open questions in a fair and unbiased way. To what extent does Professor Ford's new book meet this requirement?

The book contains eight chapters which deal with the Principles of Genetics; Sex; Evolution; Polymorphism and Mimicry; Industrial Pollution; Genetics in the Countryside and Garden; Individual Variation in Man; and Genetics and Human Societies. The contents of the book reveal that Professor Ford's coverage of the subject is far from complete, for he deals only with some aspects of classical, human and what he has called ecological genetics. There is nothing about molecular or microbial genetics, despite the fact that these are now the most actively researched areas of the science and are, moreover, ones which raise problems of great interest to the layman. This omission, furthermore, is no mere oversight, because we are told that the structure of DNA is "much beyond what is appropriate for a book of this kind" (page 30). This is surely a serious error of judgement. The reader will look in vain, therefore, for enlightenment on why, for example, there has been much public debate on the subject of genetic engineering. For this they would have to look elsewhere.

Those who are familiar with Professor Ford's style will know what to expect from this book; nor will they be disappointed, for here again we find his characteristic, enthusiastic and authoritative treatment of the subjects with which he deals and also a number of amusing and illuminating anecdotes, including one about how to plan for a scientific camp. Indeed, the book seems to be derived from two of Professor Ford's previous books, Ecological Genetics and Genetics for Medical Students, and is therefore something of an intellectual biography of his work. Those who are familiar with this work, however, will also know that there is by no means general agreement on some of the matters that are discussed. For example, apart from the obvious exception of sickle-cell anaemia, there is almost no evidence to justify the confident statement on page 151 that "heterozygous advantage is the usual method for maintaining polymorphic variation", though it is, of course, possible that some polymorphisms are maintained in this way. Then again, we do not know "that it is usual for" selective advantages "to reach 20 or 30 per cent, often much more" (page 69). The layman, however, will be unaware of these biases and hence is likely to be seriously misled when he goes on, as Professor Ford hopes he will, to pursue his interest in genetics in other works.

There are, unfortunately, other errors of emphasis and, indeed, of fact in the book. For example, we are told on page 155 that "it would be highly suspicious [my italics] if a pair of blue- or grey-eyed parents had a child with darkbrown eyes". While such an outcome would be unusual, such cases have occurred in circumstances where the paternity of the child was beyond reasonable doubt. Then again, I know of no evidence to justify the statement on page 74 , concerning the pairing of homologous chromosomes during the first division of meiosis that "allelic attraction must be stronger when the pairs are identical (homozygous) than when they are dissimilar (heterozygous)". Is it really the case that Man is more variable than other species (page 13) and that among our races, the Japanese are "much the less diversified" (page 172)? There is a particularly misleading error in the simple numerical example on page 28 which Professor Ford uses to explain how the order of genes along a chromosome may be determined from the results of a threepoint backcross (his ACB should be BAC). On page 57 we are told that if "we keep organisms in a strictly constant condition in the laboratory, all their variation is (my italics] genetic" (would that this were true!). The simple method for the detection of heterozygous advantage given on page 107 is unsatisfactory because the $\chi^{2}$ in question can be significant in the absence of this type of selection. Lastly, on page 116, where Professor Ford writes, about selfincompatibility in those species in which this is determined by a single, multi-allelic gene and control of the pollen reaction is gametophytic, that: "If both the male and female plants possess, for instance, $S 2$ and $S 2$ (one carried by the pollen, the other possessed by the stigma) fertilisation fails"'. This statement is highly misleading because it is true if and only if the comment in parenthesis is ignored (if the latter were correct the cross would be compatible). There are a number of other errors in the book, including some concerning page and author references; and the way in which some of the subject material is dealt with in the last two chapters of the book made this reader uneasy.

Reviewing this book has been a painful task, because I, like many of my colleagues in the field of ecological and population genetics, owe Professor Ford a great debt; he is one of the pioneers of the subject and has made many distinguished contributions to it. But in view of the stated aims of the book, we have a wider duty to those people for whom it is intended. With this in mind, the book cannot be recommended to the layman.

M. J. Lawrence is a Senior Lecturer in the Department of Genetics at the University of Birmingham, UK. 